\title{
Imino-4-Methoxyphenol Thiazole Derived Schiff Base Ligands: Synthesis, Spectral Characterization and Antimicrobial Activity
}

\section{Vinusha $\mathrm{HM}^{1}$, Shiva Prasad $\mathrm{K}^{2 \star}$, Chandan $\mathrm{S}^{3}$ and Muneera Begum ${ }^{1}$}

${ }^{1}$ Department of Chemistry, Sri Jayachamarajendra College of Engineering, Mysore, Karnataka, India

${ }^{2}$ Manipal Centre for Natural Sciences, Manipal University, Udupi, Karnataka, India

${ }^{3}$ Division of Biotechnology, Faculty of Life Sciences, JSS University, Mysore, Karnataka, India

\begin{abstract}
Two imino-4-methoxyphenol thiazole derived Schiff bases, 3-(5-nitrothiazol-2-ylimino)methyl)-4-methoxyphenol (4) and 3-(5-ethyl-1,3,4-thiadiazol-2-ylimino)methyl)-4-methoxyphenol (5) were synthesized by condensing 2-amino-5-nitrothiazole (1) and 2-amino-5-ethyl-1,3,4-thiadiazole (2) with 5-hydroxy-2-methoxybenzaldehyde (3). The obtained ligands were characterized by using UV-visible, ${ }^{1} \mathrm{H},{ }^{13} \mathrm{C}$-NMR and MS techniques. Data obtained from the above techniques confirmed the molecular structures of the obtained compounds. The optimized structures of the compounds were done using ACD simulation software. The synthesized compounds were tested for their antibacterial (E. coli and $R$. solanacearum) and antifungal (F. oxysporum and $A$. niger) activities. The results from these studies showed that the compounds are moderately active against the tested species of bacteria and fungi. The microbial growth inhibition by compound 4 was significantly higher than compound 5. Microbial growth inhibition activity of both the compounds was less compared with their standard drugs.
\end{abstract}

Keywords: Iminothiazole; Schiff base; NMR; Mass spectroscopy; Antimicrobial activity.

\section{Introduction}

Schiff bases will be obtained upon the condensation of primary amines with carbonyl compounds [1,2]. Intramolecular hydrogen bonding between hydroxyl $(\mathrm{OH})$ hydrogen and azomethine $(\mathrm{C}=\mathrm{N})$ nitrogen atoms of Schiff bases decides the properties of various molecular systems and plays a significant role in many biochemical mechanisms [3]. Also, $\mathrm{C}=\mathrm{N}$ linkage in the azomethine derivatives is essential for biological activity [4]. Although there are wide applications of Schiff in biological systems [5], catalysis [6] and analytical applications [7], the spectral studies of the Schiff bases containing a heterocyclic ring are comparatively minor. These Schiff bases are well known to have biological activities such as antimicrobial [8,9], antifungal $[10,11]$, antitumor [12,13] and as herbicides [14]. In particular, thiazole and derivatives have been found number of applications in medicopharmaceutical fields and also some of them were depicted to have antitumor activity [15]. Especially, benzothiazole have shown significant effect against cancer [16]. Hence the Schiff bases derived from thiazole and its compounds are expected to be biologically active. In recent years, the use of antibacterial and antifungal drugs in medicine has increased, especially with the advent of many new diseases across the globe. Efforts have focused on the development of new, less toxic and more efficacious antimicrobial drugs with novel mechanism of action.

The purpose of this study was to synthesize of some thiazole derivatives and to evaluate their activity against some species of bacteria and fungi. In the current research paper, author has reported two Schiff base compounds derived from thiazole backbone, thorough characterization and antimicrobial studies of synthesized compounds against selected species of bacteria and fungi.

\section{Materials and Methods}

\section{Chemicals and instruments}

All the chemicals and solvents were of AnalaR grade. 5-ethyl-1,3,4thiadiazol-2-amine was procured from Sigma-Aldrich, Bangalore and used as received. The spectroscopic grade solvents were used as supplied by commercial sources without any further purification. Thin layer chromatography was performed using Silica Gel G (Merck Index) pre-coated plates and the spots were visualized by exposure to UV light. ${ }^{1} \mathrm{H}$ and ${ }^{13} \mathrm{C}$-NMR spectra were recorded on a BRUKER AVANCE-400 spectrometer. Mass spectra as obtained on Bruker Daltonics 6000 plus mass spectrometer with ESI-MS mode. Antibacterial and antifungal activities of compounds under investigation was determined by Disc diffusion method [17] and Batemann poisoned technique [18], respectively.

\section{General synthesis procedure}

Schiff bases 4 and 5 was synthesized by the condensation of 2-amino-5-nitrothiazole (1) and 2-amino-5-ethyl-1,3,4-thiadiazole (2) with 5-hydroxy-2-methoxybenzaldehyde (3) in 1:1 ratio in methanol. The general synthesis route of new Schiff base compounds is depicted in Scheme 1.

Synthesis of 3-(5-nitrothiazol-2-ylimino)methyl)-4-methoxyphenol (4)

To a solution of 2-amino-5-nitrothiazole $(10 \mathrm{mmol}, 1.49 \mathrm{~g})$ in $20 \mathrm{ml}$ methanol, 5-hydroxy-2-methoxybenzaldehyde $(10 \mathrm{mmol}$, $1.57 \mathrm{~g})$ in methanol $(10 \mathrm{ml})$ was added dropwise with continuous stirring for $10 \mathrm{~min}$ and the reaction mixture was then refluxed for $6 \mathrm{~h}$ with stirring. Completion of the reaction was monitored time-

*Corresponding author: Shiva Prasad K, Manipal Centre for Natural Sciences, Manipal University, Udupi, Karnataka - 576 104, India, Tel: +91-820-292 3571; Fax: +91-820-257 0062; E-mail: shivaprasad.k@manipal.edu

Received August 04, 2015; Accepted August 05, 2015; Published August 12, 2015

Citation: Vinusha HM, Shiva Prasad K, Chandan S, Muneera Begum (2015) Imino-4-Methoxyphenol Thiazole Derived Schiff Base Ligands: Synthesis, Spectral Characterization and Antimicrobial Activity. Chem Sci J 6: 102. doi:10.4172/21503494.1000102

Copyright: (C) 2015 Mariswamy VH, et al. This is an open-access article distributed under the terms of the Creative Commons Attribution License, which permits unrestricted use, distribution, and reproduction in any medium, provided the original author and source are credited. 


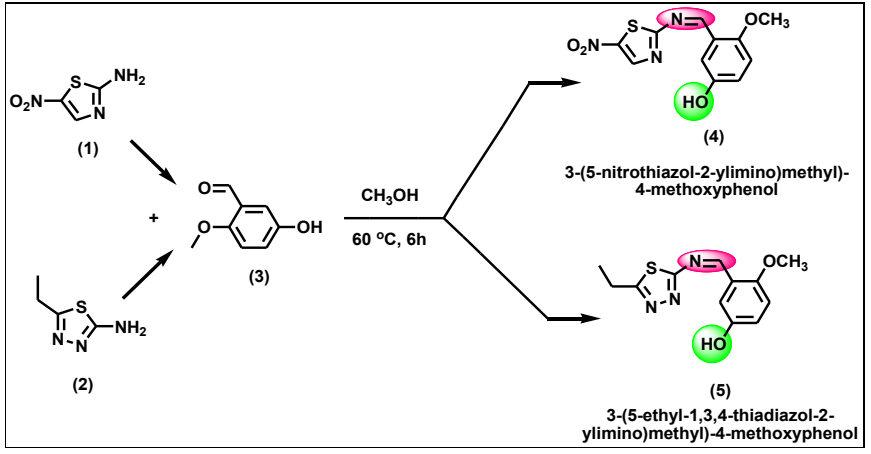

Scheme 1: Synthesis of thiazole Schiff base derivatives (4 and 5).

to-time by TLC. After the completion, the reaction mixture was precipitated by pouring into ice cold water, filtered, dried and stored in vacuum desiccator. Yield: $82 \% .{ }^{1} \mathrm{H}$ NMR (DMSO- $\left.\mathrm{d}_{6}, \mathrm{ppm}\right), \delta 10.36$ (s, $1 \mathrm{H}, \mathrm{OH})$, ), $8.43(\mathrm{~s}, 1 \mathrm{H}$, imine $\mathrm{CH}), 7.78(\mathrm{~d}, 1 \mathrm{H}, \mathrm{Ar}-\mathrm{H}), 7.71(\mathrm{~d}, 1 \mathrm{H}$, Ar-H), 3.51 (s, $\left.3 \mathrm{H}, \mathrm{OCH}_{3}\right) ;{ }^{13} \mathrm{C}$ NMR (DMSO-d 6 , ppm), $\delta$ 171.2, 135.8, $131.4,130.5,130.3,129.7,129.3,128.4,127.9,126.2,50.1$. ESI-MS calc. for $\mathrm{C}_{11} \mathrm{H}_{9} \mathrm{~N}_{3} \mathrm{O}_{4} \mathrm{~S}[\mathrm{M}+\mathrm{K}]^{+}$: 318.03; found 318.27.

Synthesis of 3-(5-ethyl-1,3,4-thiadiazol-2-ylimino)methyl)-4methoxyphenol (5)

To a solution of 2-amino-5-ethyl-1,3,4-thiadiazole (10 mmol, 1.30 g) in $20 \mathrm{ml}$ methanol, 5-hydroxy-2-methoxybenzaldehyde $(10 \mathrm{mmol}$, $1.57 \mathrm{~g})$ in methanol $(10 \mathrm{ml})$ was added dropwise with continuous stirring for $10 \mathrm{~min}$ and the reaction mixture was then refluxed for $6 \mathrm{~h}$ with stirring. Completion of the reaction was monitored time-to-time by TLC. After the completion, the reaction mixture was precipitated by pouring into ice cold water, filtered, dried and stored in vacuum desiccator. Yield: 79\%. ${ }^{1} \mathrm{H}$ NMR (DMSO- $\left.\mathrm{d}_{6}, \mathrm{ppm}\right), \delta 8.37(\mathrm{~s}, 1 \mathrm{H}$, imine $\mathrm{CH}), 7.78(\mathrm{~d}, 1 \mathrm{H}), 7.71(\mathrm{~d}, 1 \mathrm{H}), 3.68(\mathrm{~s}, 3 \mathrm{H}), 2.68(\mathrm{q}, 2 \mathrm{H}), 1.32(\mathrm{t}, 3 \mathrm{H})$; ${ }^{13} \mathrm{C}$ NMR (DMSO-d $\mathrm{d}_{6}$ ppm), $\delta 170.7,135.5,130.8,130.1,129.1,128.9$, $127.8,127.4,125.9,53.4,24.6,15.2$. ESI-MS calc. for $\mathrm{C}_{12} \mathrm{H}_{13} \mathrm{~N}_{3} \mathrm{O}_{2} \mathrm{~S}[\mathrm{M}+$ $\mathrm{Na}]^{+}:$286.92; found 286.10 .

\section{Antimicrobial Screening}

\section{Antibacterial screening by disc diffusion method}

Antibacterial activity of test compounds 4 and 5 was determined against $E$. coli and R. solanacearum. The pure cultures of these organisms were obtained from the Division of Biotechnology, JSS University, Mysore-15. The organisms used in the present study were sub-cultured in to sterile nutrient broth. After incubating the same at $37^{\circ} \mathrm{C}$ for $3 \mathrm{~h}$ the growth thus obtained was used as inoculums for the tests. A known weight of the compound was allowed to dissolve in DMSO for $30 \mathrm{~min}$ in suitable sterile test tubes.

The agar medium was melted on water bath and cooled to $45^{\circ} \mathrm{C}$. To the molten agar $(20-25 \mathrm{ml}) 0.5$ to $0.7 \mathrm{ml}$ of $3 \mathrm{~h}$ old sub culture was added aseptically and mixed well by gentle shaking. This was poured into petri dishes and allowed to attain room temperature. The sterilized filter paper disks (Whatman 41) were loaded with known volume of the test compound of known strength using micropipette, to get the disk of desired concentration. The disks are placed over the growth media seeded with microorganisms, left for diffusion and incubated at $37 \pm$ $2^{\circ} \mathrm{C}$ for $24 \mathrm{~h}$. The experiment was carried out with four replicates for each concentration. The antibiotic Chloramphenicol was also screened under similar conditions for comparison as a standard and the solvent DMSO was also put to know the activity (control). The antibacterial activity was estimated on the basis of the size of inhibition zone formed around disks on the seeded agar plates. The mean diameter of inhibition zone developed (in $\mathrm{mm}$ ) for each concentration was measured.

\section{Antifungal screening by Batemann poisoned technique}

Antifungal activity of the test compounds was determined against two fungi A. flavus and A. Niger. The pure cultures of these organisms were obtained from the Division of Biotechnology, JSS University, Mysore-15. The fungi A. flavus and A. Niger were cultured for seven days on Czapek's agar in sterilized petridishes under 12/12 h light and darkness. Colonies were isolated for fungicidal studies after growing to required diameter. The testing compounds (dissolved in DMSO) were added to $10-15 \mathrm{ml}$ of sterilized media to achieve concentration at $35 \pm 3^{\circ} \mathrm{C}$ allowed the media for solidification. The fungi $A$. flavus and $A$. Niger were taken as $2 \mathrm{~mm}$ disks from 10 days old pure colonies and placed in the petriplates containing Capek's agar nutrient medium. The experiments were carried out in four replicates per treatment and incubation was carried out at $22 \pm 1^{\circ} \mathrm{C}$ under $12 / 12 \mathrm{~h}$ light and darkness. The radial growth of the colony was recorded after $96 \mathrm{~h}$ of incubation and mean diameter of mycelia growth in each treatment was recorded. The average percentage inhibition was calculated on the growth media compared to controls using the Vincent formula [19].

\section{Results and Discussion}

The synthetic route of Schiff base compounds 4 and 5 is represented in Scheme 1. The reported compounds were synthesized by following literature procedures [20]. The compounds have been characterized by NMR $\left({ }^{1} \mathrm{H}\right.$ and $\left.{ }^{13} \mathrm{C}\right)$, MS and UV-Vis spectroscopic techniques.

The representative NMR $\left({ }^{1} \mathrm{H}\right.$ and $\left.{ }^{13} \mathrm{C}\right)$ spectra of compound 4 are shown in Figure 1 . The ${ }^{1} \mathrm{H}$ NMR spectra of the compounds provide useful information about the imine $\mathrm{CH}$ protons which exhibited resonance in the region $\delta 8.25-8.43$ (Figure 1a and 1b). A broad singlet at $\delta 10.36$ in the proton NMR spectrum of 4 is observed due the -OH group. Mass spectrum of compound 4 is shown in Figure 2. The detailed data obtained for ${ }^{1} \mathrm{H},{ }^{13} \mathrm{C}$ and $\mathrm{MS}$ of the reported compounds are provided in the experimental section.

The UV-Vis absorption spectra of the compounds 4 and 5 are recorded in ethanol at ambient temperature. As shown in Figure 3, the UV-Vis spectra of 4 and 5 exhibits four bands each and out of which two bands are encountered towards higher energy in the region 219246 and 221-252 nm, respectively. These bands are due to transition of $\pi$ electrons in the aromatic rings. ( $\pi-\pi^{*}$ transition). The third and fourth bands in both the compounds appears more or less in the same region around 275-347 nm due to $\pi-\pi^{*}$ transition within the imine group and $362-459 \mathrm{~nm}$ due to an intramolecular charge transfer interactions within the whole molecule [21].

\section{Antimicrobial Activity}

The biological results obtained are presented in the Table 1. In this study, the concentration of the test compounds and standard drugs were at $400 \mathrm{ppm}$ in DMSO. The test compounds 4 and 5 showed less inhibition of the bacterial growth in comparison with standard drug Chloramphenicol. Both the compounds showed same inhibition potential against E. coli but compound 4 showed high inhibition effect than compound 5 against $R$. solanacearum (Supplementary Figures). The reason for this increased inhibition effect may be due to the presence of electron withdrawing nitro group in compound 4 

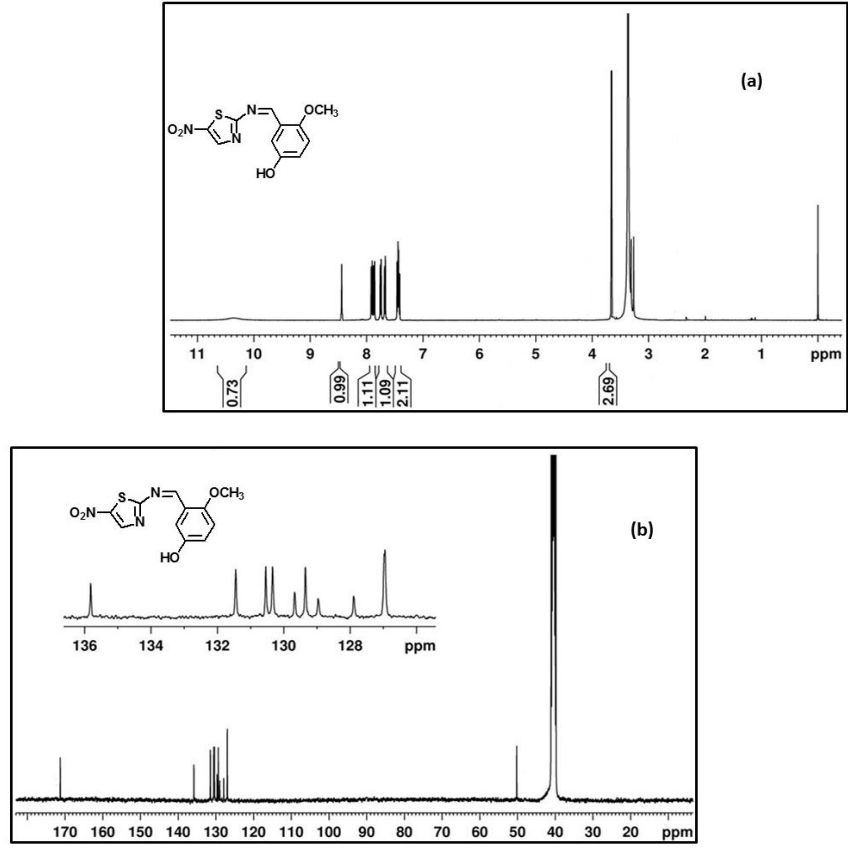

Figure 1: (a) ${ }^{1} \mathrm{H}$ NMR and (b) ${ }^{13} \mathrm{C}$ NMR of 3-(5-nitrothiazol-2-ylimino)methyl)-4methoxyphenol (4).

\begin{tabular}{|c|c|c|c|c|}
\hline \multirow{2}{*}{ Compound } & \multicolumn{2}{|c|}{$\begin{array}{c}\text { Antibacterial activity in } \\
(\mathbf{m m})^{*}\end{array}$} & \multicolumn{2}{c|}{ Antifungal activity in (mm) } \\
\cline { 2 - 5 } & E. coli & $\begin{array}{c}\text { R. } \\
\text { solanacearum }\end{array}$ & F. oxysporum & A. niger \\
\hline 4 & 10 & 11 & 15 & 14 \\
\hline 5 & 10 & 09 & 13 & 10 \\
\hline Chloramphenicol & 12 & 12 & - & - \\
\hline Fluconazole & - & - & 18 & 18 \\
\hline
\end{tabular}

Table 1: Antibacterial and antifungal activities of Schiff base compounds. *Zone of inhibition (average of four replicates).

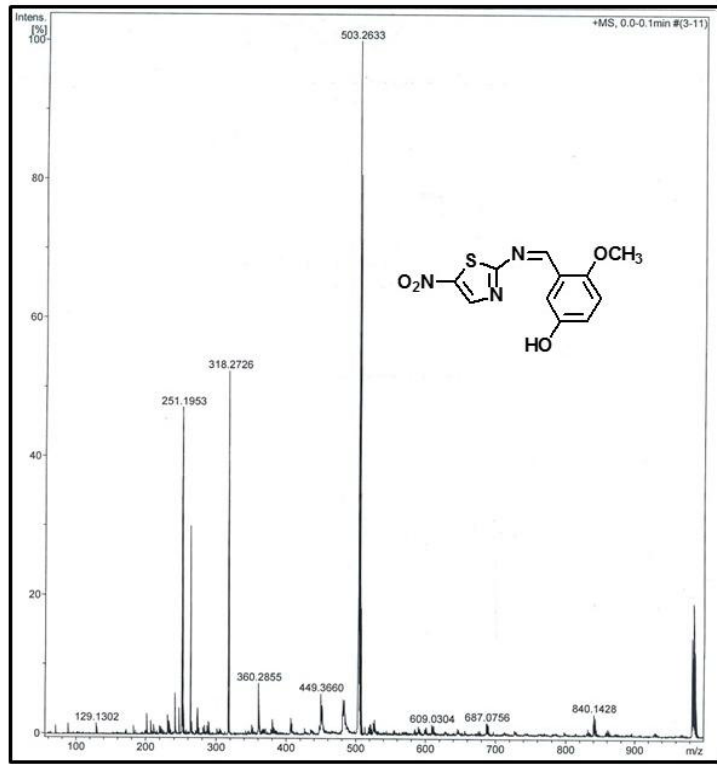

Figure 2: Mass spectrum of 3-(5-nitrothiazol-2-ylimino)methyl)-4-methoxyphenol (4).

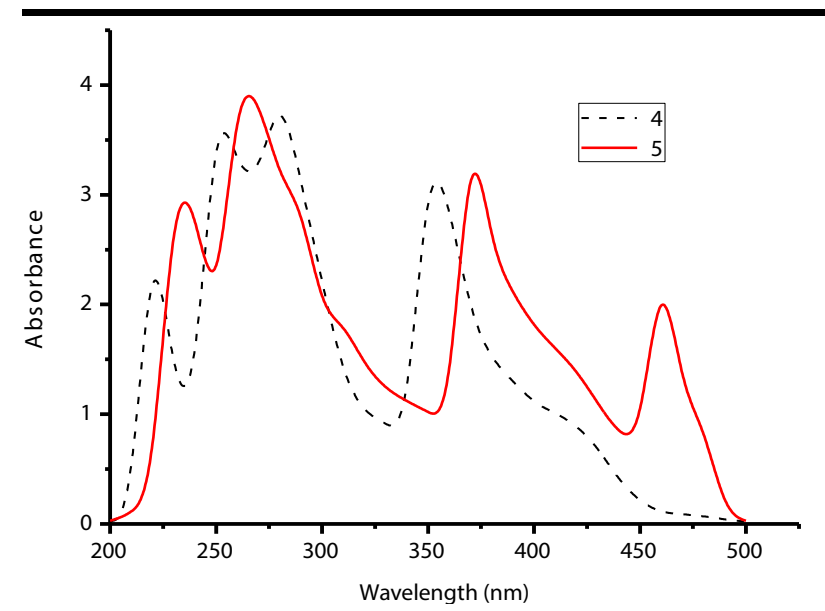

Figure 3: UV-Visible absorption spectra of Schiff base compounds (4 and 5).

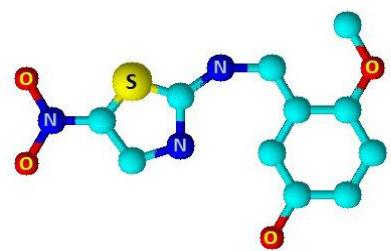

4

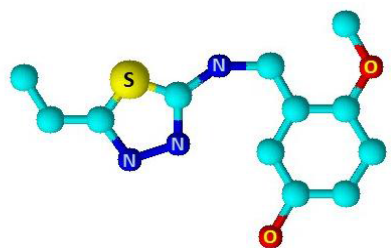

Figure 4: Simulated structures of Schiff base compounds (4 and 5).

[22]. Similar situation was noticed in antifungal studies. The standard antifungal drug, fluconazole was found more potent than the tested compounds. Here also compound 4 was found more potent than compound 5 against the selected species of fungi. The most probable reason for the inhibition would be the interaction of tested compounds with the membrane proteins of the microbes which will cause the rupture of membrane due to alter in the protein structure and thus growth inhibition [23].

\section{Conclusion}

We describe the synthesis of 3-(5-nitrothiazol-2-ylimino) methyl)-4-methoxyphenol (4) and 3-(5-ethyl-1,3,4-thiadiazol2-ylimino)methyl)-4-methoxyphenol (5). The synthesized compounds were characterized using various spectral techniques. The antimicrobial activity of the two methoxyimio thiazole derived Schiff bases, 4 and 5 were tested against selected species of bacterial (E. coli and R. solanacearum) and fungi (F. oxysporum and A. niger). Both the compounds were moderately potent towards the microbial growth inhibition. Particularly, compound 4 was significantly active against the tested microbes than compound 5 . The possible reason for this potency of compound 4 may be due to the presence of electron withdrawing nitro group which can alter the tertiary structure of membrane proteins and thus growth. The simulated structures of the compounds are depicted in Figure 4 which was done by using ACD molecular simulation package software.

\section{Conflict of Interest}

Authors declare that there is no conflict of interest regarding publication of this research work. 
Citation: Vinusha HM, Shiva Prasad K, Chandan S, Muneera Begum (2015) Imino-4-Methoxyphenol Thiazole Derived Schiff Base Ligands: Synthesis, Spectral Characterization and Antimicrobial Activity. Chem Sci J 6: 102. doi:10.4172/2150-3494.1000102

\section{Acknowledgement}

One of the author, Dr. K. Shiva Prasad thank Prof. Mohini Gupta, Director Manipal Centre for Natural Sciences, Manipal University for providing mora support and other basic facilities. Ms. H. M. Vinusha and Mrs. Muneera Begum wish to acknowledge Principal, SJCE, Mysore for providing laboratory facilities. Dr. $\mathrm{S}$. Chandan extends his acknowledgment to the Head, Division of Biotechnology, Faculty of Life sciences, JSS University, Mysore for permitting to conduct biological studies.

\section{References}

1. Shibuya Y, Nabari K, Kondo M, Yasue S, Maeda K, et al. (2008) The Copper(II) Complex with Two Didentate Schiff Base Ligands. The Unique rearrangement that Proceeds under Alcohol Vapor in the Solid State to Construct Noninclusion Structure. Chemistry Letters 37: 78-79.

2. Bera M, Mukhopadhyay U, Ray D (2008) Iron(III) induced 2-phenyl imidazolidine ring hydrolysis of a new binucleating Schiff base ligand: X-ray structure of the mononuclear Fe"l'(NNO) ${ }_{2}$ end product. Inorganica Chemica Acta 358: 437-443.

3. Szady-Chelmieniecka A, Grech E, Rozwadowski Z, Dziembowska T, Schilf W, et al. (2001) Multinuclear NMR study of the intramolecular hydrogen bond in Schiff-Mannich bases. Journal of Molecular Structure 565: 125-128.

4. Dhanaraj CJ, Nair MS (2009) Synthesis, characterization, and antimicrobial studies of some Schiff-base metal(II) complexes. Journal of Coordination Chemistry 62: 4018-4028.

5. Maurer RI, Blover PI, Dilworth JR, Reynoh CA (2002) Studies on the mechanism of hypoxic selectivity in copper bis(thiosemicarbazone) radiopharmaceuticals. $J$ Med Chem 45: 1420-1431.

6. Vasin SV, Cetralla J, Genogel RA, Bernal (1990) FT-IR \& UV/Vis Spectroscopic Study of Some Schiff bases Derived from amino Benzoic acid and Bromo benzaldehyde. Journal of Inorganic Chemistry 29: 885-890.

7. Khedr AM, Gaber M, Issa RM, Erten H (2005) Synthesis and spectral studies of 5-[3-(1,2,4-triazolyl-azo]-2,4-dihydroxybenzaldehyde (TA) and its Schiff bases with 1,3-diaminopropane (TAAP) and 1,6-diaminohexane (TAAH). Their analytical application for spectrophotometric microdetermination of cobalt(II). Application in some radiochemical studies. Dyes and Pigments 67: 117-126.

8. El-Masry AH, Fahmy HH, Abdelwahed SHA (2000) Synthesis and antimicrobial activity of some new benzimidazole derivatives. Molecules 5: 1429-1438.

9. More PG, Bhalvankar RB, Pattar SC (2001) Synthesis and biological activities of Schiff bases of aminothiazoles. Journal of Indian Chemical Society 78: 474475

10. Baseer MA, Jadhav VD, Phule RM, Archana YV, Vibhute YB (2000) Synthesis and antimicrobial activity of some new Schiff bases. Oriental Journal of Chemistry 16: 553-556.
11. Pandeya SN, Sriram D, Nath G, De Clercq E (1999) Synthesis and antimicrobial activity of Schiff and Mannich bases of isatin and its derivatives with pyrimidine. IL Farmaco 54: 624-628.

12. Desai SB, Desai $P B$, Desai KR (2001) Synthesis of some Schiff bases, thiazolidones, and azetidinones derived from 2,6-diaminobenzo[1,2-d:4,5- $\left.d^{\prime}\right]$ bisthiazole and their anticancer activities. Heterocyclic Communications 7: 8390.

13. Pathak P, Jolly VS, Sharma KP (2000) Synthesis and biological activities of some new substituted arylazo Schiff bases. Oriental Journal of Chemistry 16 : 161-162.

14. Samadhiya S, Halve A (2001) Synthetic utility of Schiff bases as potential herbicidal agents. Oriental Journal of Chemistry 17: 119-122.

15. Bradshaw TD (2002) Preclinical Evaluation of Amino Acid Prodrugs of Nove Antitumor 2-(4-Amino-3-Methylphenyl) Benzothiazoles. Molecular Cancer therapeutics 1: 239-246.

16. Swarnkar PK, Kriplani P, Gupta GN, Ojaha KG (2007) Microbial transformations of 2-substituted benzothiazoles. Indian Journal of Chemistry 4: 14-18.

17. Barry AL (1980) Procedure for testing antimicrobial agents in agar media Theoretical consideration in Antibiotics in Laboratory Medicine, V. Lorian, $\left(2^{\text {nd }}\right.$ edn) Williams and Wilkins, London, United Kingdom.

18. Barry AL (1976) Antibiotic susceptibility Test: Principles and Practice, Lea and Febiger, Philadelphia.

19. Bateman E (1993) The effect of concentration of the toxicity of chemicals to living organisms. US department agriculture technical bulletins 1: 338-346.

20. Shiva Prasad K, Shiva Kumar L, Revanasiddappa HD, Melvin Prasad Jayalakshmi B (2011) Synthesis, spectral characterization, DNA interaction studies, anthelmintic and antimicrobial activity of transition metal complexes with 3-(2-hydroxybenzylideneamino)-2-methylquinazolin-4(3H)-one and 1,10-phenanthroline. Biointerface Research in Applied Chemistry 1: 127-138.

21. Raafat Issa M, Abdalla Khedr M, Helen Rizk (2008) ${ }^{1} \mathrm{H}$ NMR, IR and UVIVIS Spectroscopic Studies of Some Schiff Bases Derived from 2-Aminobenzothiazole and 2-Amino-3-Hydroxypyridine. Journal of the Chinese Chemical Society 55: 875-884.

22. Gerald Berkelhammer, Goro Asato (1972) Nitroheterocyclic antimicrobia agents: 1-Methyl-2-nitro-5-imidazolyl derivatives. Journal of Medicinal Chemistry 15: 1086-1088.

23. Shiva Prasad K, Shiva Kumar L, Chandra Shekar S, Melvin Prasad Revanasiddappa HD (2011) Oxovanadium Complexes with Bidentate N, O Ligands: Synthesis, Characterization, DNA Binding, Nuclease Activity and Antimicrobial Studies. Chemical Sciences Journal 1: 1-10. 